\title{
Response to letter to editor
}

\section{R. Rajakulasingam ${ }^{1}$ (D) A. Saifuddin ${ }^{1}$}

Received: 3 July 2020 / Revised: 3 July 2020 / Accepted: 27 July 2020 / Published online: 30 July 2020

(C) ISS 2020

We read with interest the letter to the editor regarding our recently published Test Yourself Case depicting 'Langer's axillary arch.' Georgiev et al. highlights the origin and history of the term, which indeed is a long one and well beyond the scope of the Test Yourself Case format.

First described in 1783 by Bugnone according to Pitzorno et al. in 1911 [1], and around 1793 by Ramsay et al. in his own account of 1812 [2], this variant became of interest to Langer in 1846 [3]. Langer initially mentioned a fibrous arch without muscular fibres while the former two authors described a muscular variation. The author points out that the commonly used term 'Langer's axillary arch,' referring to 'arc axillaire de Langer,' or 'axillary arch of Langer,' mentioned by Testut et al. [4] upon discovering the previous dissection studies, and the association has remained ever since. More recently however, the term 'axillopectoral muscle' has been used by Turgut et al. in 2005 [5]. While this detailed history is certainly interesting, the term used in our original manuscript merely reflects the descriptors and origin most readers would have been aware of. We thank the author for highlighting that Langer's original publication was dated 1846 and not 1894.

Georgiev et al. also highlights two further insertional sites of the axillary arch, specifically citing the pectoralis minor muscle and axillary fascia. In addition, further sites have been reported in literature including the long head of triceps brachii tendon, teres major, medial humeral epicondyle, medial intermuscular septum, and lateral lip of the intertubercular humeral groove $[6,7]$. The list given in the original manuscript was not meant to be exhaustive but covers the main insertional sites, which are muscle slips extending from latissimus dorsi to pectoralis major, short head of the biceps brachii, or coracoid process. We anticipate detailed cadaveric dissection studies revealing even more variants and new insertional sites. The existence of three or four fascicles has been identified already, but without morphological description by Carl Langer himself in 1846 [3].

We thank the author for taking the time to respond to our original manuscript and broach this interesting topic.

\section{References}

1. Pitzorno H. Contributo alla morfologia dell'arco ascellare musculare di Langer. Arch Ital Anat Embryol. 1911;10:129-44.

2. Ramsay A. An account of unusual conformation of some muscles and vessels. Edinburgh Med Surg J. 1812;8:281-3.

3. Langer C. Zur anatomie des musculus latissimus dorsi. Österr Med Wochenschrift. 1846;15:454-8.

4. Testut L Les anomalies musculaires chez 'homme expliquees par l'anatomie comparee. Leur importance en anthropologie. 1884. Paris: Masson. p7-118.

5. Turgut HB, Peker T, Gulekon N, Anil A, Karakose M. Axillopectoral muscle (Langer's muscle). Clin Anat. 2005;183: 220-3.

6. Lama P, Tamang B. A common insertion of thoracoepicondylaris and an axillary arch of Langer: a case report. Int J Anat Var. 2010;3: 63-4.

7. Lama P, Potu BK, Bhat KM. Chondrohumeralis and axillary arch of Langer: a rare combination of variant muscles with unique insertion. Romanian J Morphol Embryol. 2010;51(2):395-7.

Publisher's note Springer Nature remains neutral with regard to jurisdictional claims in published maps and institutional affiliations.

R. Rajakulasingam

Ramanan.rajakulasingam1@nhs.net

A. Saifuddin

Asif.Saifuddin@nhs.net

1 Department of medical imaging, Royal National Orthopaedic Hospital, Brockley Hill, Stanmore HA7 4LP, UK 